\title{
EBSD Analysis Optimised for Twin-related Boundaries
}

\author{
Valerie Randle
}

Dept. Materials Engineering, University of Wales Swansea, Swansea SA2 8PP, UK.

The nickel-based superalloy Nimonic PE16 is precipitation strengthened by the presence of gammaprime. Overaging the alloy results in an increase in the pinning force on the boundary of at least a factor of two, and the grain size is very stable when the alloy is annealed below the gamma-prime solvus, namely $880^{\circ} \mathrm{C}[1,2]$. Another microstructural feature of PE16 is that annealing twins are readily formed because of its low stacking-fault energy. Experiments have been conducted to explore the evolution of grain boundary parameters in PE16. Specimens of commercially heat treated PE16 were annealed in air at $850^{\circ} \mathrm{C}$, i.e. $30^{\circ} \mathrm{C}$ below the gamma-prime solvus, for times of $1 \mathrm{~h}, 10 \mathrm{~h}$ and $100 \mathrm{~h}$. Misorientation data across interfaces were obtained by use of an electron back-scatter diffraction (EBSD) system from HKL Technology in a Philips XL30 SEM [3]. Several orientation maps with a grid step size of $0.5 \mu \mathrm{m}$ were collected and analysed from each specimen.

Figure 1 shows a typical example of an orientation map from overaged PE16. In the coincidence site lattice (CSL) system boundaries are categorised by $\Sigma$, the reciprocal density of coinciding sites. In figure $1 \Sigma 3$ boundaries are represented as thick white lines, $\Sigma 9$ and $\Sigma 27$ boundaries are thin white lines and other boundaries are black. The statistics for the $\Sigma 3^{\mathrm{n}}$ family are shown in figure 2. Apart from $\Sigma 3$, plus some $\Sigma 9$ and $\Sigma 27$, there were almost no other $\Sigma$ boundaries recorded. There was a small increase in $\Sigma 3$ proportion from $43 \%$ after $1 \mathrm{~h}$ annealing to $50 \%$ after $100 \mathrm{~h}$. More than $90 \%$ of the total length of $\Sigma 3$ in the map is within $2^{\circ}$ of the exact reference misorientation, which indicates that these $\Sigma 3 \mathrm{~s}$ are predominantly annealing twins. The remaining $10 \%$ of $\Sigma 3$ length deviates by more than $2^{\circ}$ from the reference structure. It is evident from the morphology of these higher deviation $\Sigma 3 \mathrm{~s}$ that they are more akin to grain boundaries than to twins.

Higher $\Sigma 3^{\mathrm{n}}$ boundaries in the microstructure are usually generated by impingement of two appropriate $\Sigma 3^{\mathrm{n}}$ boundaries, e.g. $\Sigma 3+\Sigma 3 \rightarrow 9, \Sigma 3+\Sigma 9 \rightarrow 27$. The proportions of $\Sigma 9$ and $\Sigma 27$ in the present data are particularly low, which is an indication that there has been little movement and interaction of $\Sigma 3 \mathrm{~s}$, hence disallowing their impingement. This also explains why most $\Sigma 3 \mathrm{~s}$ are twins: there has been very little impingement to produce $\Sigma 3 \mathrm{~s}$ via 'back' reactions of the type $\Sigma 9+\Sigma 3 \rightarrow \Sigma 3$, which is expounded in the ' $\Sigma 3$ regeneration model' [4]. This near-stagnation in the grain boundary population is a result of the strong grain boundary pinning by gamma-prime precipitates which inhibited grain boundary migration.

\section{References}

[1] W. Betteridge and J. Heslop, The Nimonic Alloys, Edward Arnold, London, 1974.

[2] V. Randle and B. Ralph, Acta Metall. 34 (1986) 891.

[3] V. Randle and O. Engler, 'Introduction to Texture Analysis: Macrotexture, Microtexture and Orientation Mapping', Gordon and Breach, London, 2000.

[4] V. Randle, Acta Mater. 47 (1999) 4187. 


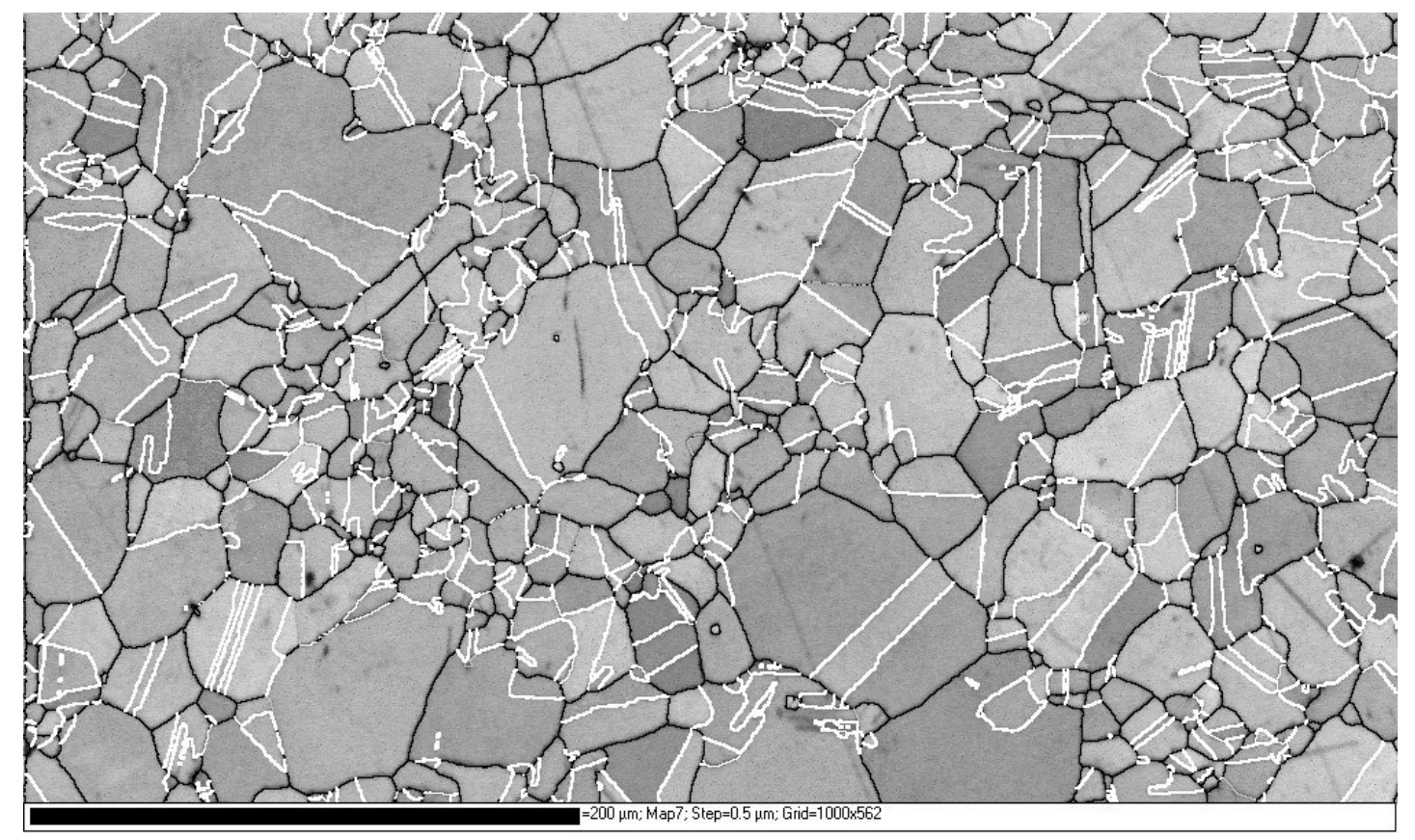

Figure 1. Example of an orientation map from PE16 after annealing for 10h. $\Sigma 3$ boundaries are represented as thick white lines, $\Sigma 9$ and $\Sigma 27$ boundaries are thin white lines and other boundaries are black.

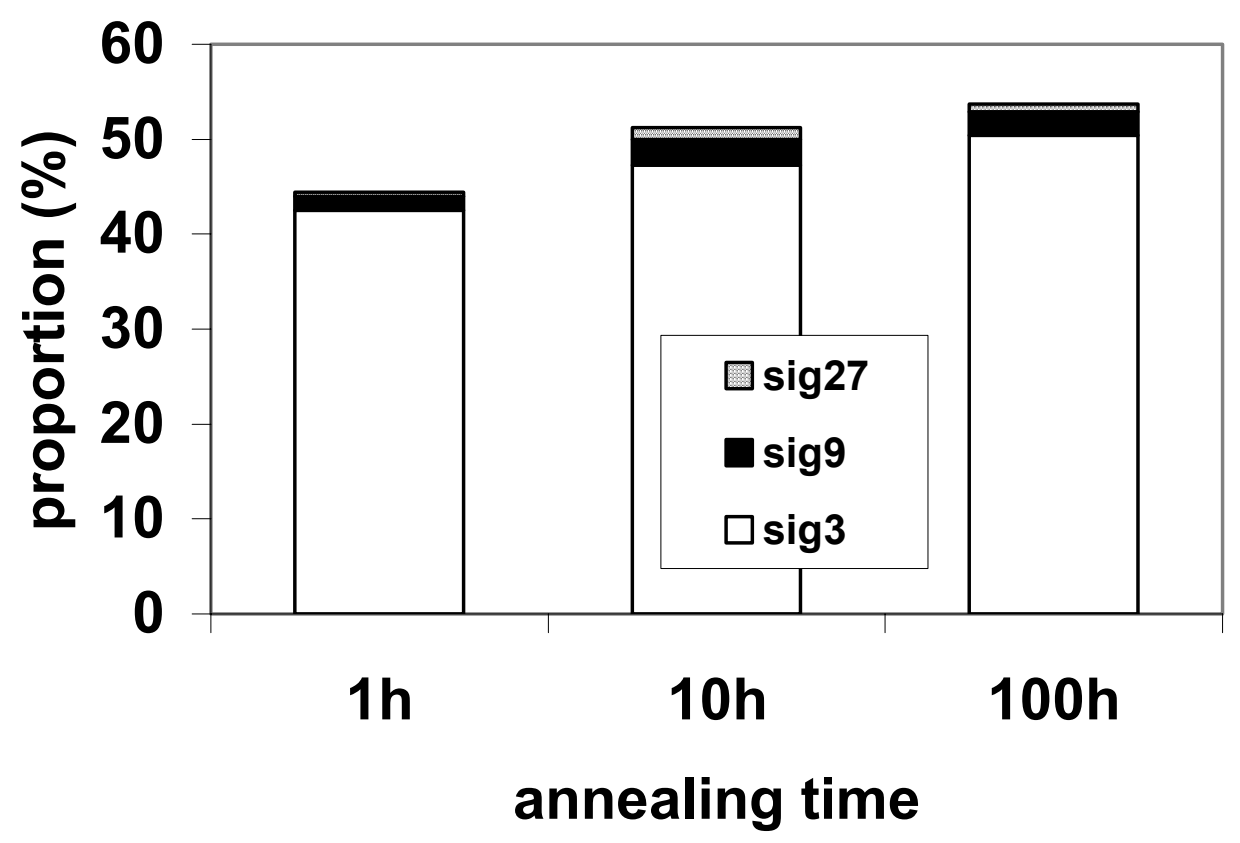

Figure 2. Proportions of $\Sigma 3^{\mathrm{n}}$ boundaries after $1 \mathrm{~h}, 10 \mathrm{~h}$ and $100 \mathrm{~h}$ annealing below the gamma-prime solvus. The scale bar is $100 \mu \mathrm{m}$. 